https://helda.helsinki.fi

\title{
Data Hugging in European Biobank Networks
}

\section{Tupasela, Aaro}

2021-10-02

Tupasela, A 2021 , ' Data Hugging in European Biobank Networks ', Science as Culture, vol. 30 , no. 4 , pp. 513-534 . https://doi.org/10.1080/09505431.2021.1949274

http://hdl.handle.net/10138/336579

https://doi.org/10.1080/09505431.2021.1949274

cc_by_nc_nd

publishedVersion

Downloaded from Helda, University of Helsinki institutional repository.

This is an electronic reprint of the original article.

This reprint may differ from the original in pagination and typographic detail.

Please cite the original version. 


\section{Data Hugging in European Biobank Networks}

\section{Aaro Tupasela}

To cite this article: Aaro Tupasela (2021) Data Hugging in European Biobank Networks, Science as Culture, 30:4, 513-534, DOI: 10.1080/09505431.2021.1949274

To link to this article: https://doi.org/10.1080/09505431.2021.1949274
(c) 2021 The Author(s). Published by Informa UK Limited, trading as Taylor \& Francis Group

\section{Published online: 07 Jul 2021.}

Submit your article to this journal $₫$

Џll Article views: 728

Q View related articles ๘

View Crossmark data \lceil

4 Citing articles: 2 View citing articles 진 


\title{
Data Hugging in European Biobank Networks
}

\author{
Aaro Tupasela \\ Faculty of Social Sciences, University of Helsinki, Helsinki, Finland
}

\begin{abstract}
The sharing, circulation, distribution, and use of human tissue samples and related data have become a major political and scientific pre-occupation during the past two decades. In the age of big data, the political, scientific, and economic momentum around the need to increasingly collect and collate massive amounts of data has intensified. At the same time, the control and sharing of samples and data have become increasingly strategic in positioning biobanks within the global biomedical research market. Numerous commentators have identified several reasons why and with whom biobanks choose to share. Despite intensified efforts to encourage sharing within networks, there are still actors who have not embraced the values of sharing. The term 'data hugging' is introduced as a form of data work through which value is generated but sharing as a practice is not exercised according to community expectations. Data hugging is a term used within the biobanking community to describe the practice of withholding samples or data from other network members. While some biobankers consider data hugging to be an impediment to efficient and responsible science, it can also be another way of generating value in an otherwise challenging value creation environment. European biobanking policies, as well as the biobanking community, need a better understanding of these value-generating practices in relation to the life cycle of the biobank.
\end{abstract}

\section{KEYWORDS}

Biobanks; data hugging; big data; data sharing

\section{Introduction}

The sharing of data and samples has emerged as a major political and scientific pre-occupation within discussions surrounding human tissue biobanking ${ }^{1}$ (Gottweis and Petersen, 2008; Kaye et al., 2009; Yuille et al., 2008). Data and sample sharing have gone together with the development of new research infrastructures, which policymakers, as well as scientists, hope will serve as a catalyst for innovation and development (Tarkkala et al., 2019). Langhof et al. (2017) have identified more than 1100 biobanks in Europe and the United States

CONTACT Aaro Tupasela $\otimes$ aaro.tupasela@helsinki.fi E Faculty of Social Sciences, University of Helsinki, Unioninkatu 35, 00014 Helsinki, Finland 9 @AaroTupasela

(c) 2021 The Author(s). Published by Informa UK Limited, trading as Taylor \& Francis Group

This is an Open Access article distributed under the terms of the Creative Commons Attribution-NonCommercial-NoDerivatives License (http://creativecommons.org/licenses/by-nc-nd/4.0/), which permits non-commercial re-use, distribution, and reproduction in any medium, provided the original work is properly cited, and is not altered, transformed, or built upon in any way. 
alone, many of which have received substantial amounts of public funding to develop their collections. One such infrastructure is the European research infrastructure for biobanking (BBMRI-ERIC) (Viertler and Zatloukal, 2008; Litton, 2018). The research network includes 20 countries, as well as the World Health Organization (WHO), and is one of the largest in Europe (BBMRI-ERIC, 2020).

One of the goals of the research infrastructures is to develop sample and data-sharing practices among member countries, as well as facilitate the dissemination of good biobanking standards and the harmonization of guidelines and legislation regarding biobanking in Europe. BBMRI-ERIC differs from research projects in that the funding received from the European Union (EU) is meant to build a research infrastructure and not fund research. These research infrastructures are to facilitate sample and data sharing among its members. Although the network has been researcher initiated, it has been well supported by the EU and considered an important research infrastructure.

A central feature of its services has been the creation of a sample catalog, which allows researchers to find the samples and data that they may need for their research. To date, the catalog contains information on more than 500 biobanks. From the outset, one of the goals of BBMRI-ERIC has been to promote sampleand data-sharing practices among its members. Membership in the network is voluntary and requires that researchers convince their national funding agencies to become national members. As such, the network is a vehicle for sample and data sharing. Sample and data sharing, however, are far more nuanced. Many network members have criticized the lack of sharing by others in the network and have been perplexed as to why some have joined a sharing network if they do not share. As such, a broad range of responses by network members has met the normative goals regarding access and sharing.

Within the context of European biobank sample sharing, the purpose of this article is to ask why some biobank managers and researchers choose not share their samples and data, despite the network's explicit goal to do so? What factors contribute to the alternative forms of valuation that are taking place in relation to biobank samples and data? Although members of networks share a common goal of increasing the value of their activities, samples, and data, the means through which valuation may take place can differ significantly between actors (cf. Tupasela, 2006). Within this context, data hugging represents a particular substantiation of data work and value creation, which appears antithetical to the norms of the network. Given that public funding heavily supports the vast majority of biobanking activities, the exploration of data hugging as a practice of value creation suggests that not all forms of value are in line with the policy and funding expectations that have emerged during the past decade.

Within the European context, several supra-national organizations have sought to encourage data-sharing strategies (OECD, 2001, 2006, 2009; 
European Society of Human Genetics (ESHG), 2003; Laurie, 2004). These datasharing strategies also apply to physical samples (Pereira, 2013). More recent Horizon 2020 visions and strategies build on this earlier work, emphasizing sustainable growth strategies (European Commission, 2010) and the central role that data play in economic growth (Zuiderwijk et al., 2012). From a historical perspective, data and sample sharing builds on the so-called knowledge-based bioeconomy policies (European Commission, 2005; Potocnik, 2005; Goven and Pavone, 2015), where production and value creation are increasingly seen to be based on data and its assetization (Birch and Tyfield, 2013; Birch and Muniesa, 2020). For the bioeconomy, the human genome project, the health sector, and the related samples and health data have been major contributors to such development (Tripp and Grueber, 2011; Hood and Rowen, 2013; Florio, 2019).

In addition, because university-based research groups are publicly funded, they are rarely provided with funds, which would allow them to gain access to expensive tissue and data resources in the first place. In this sense, the profit-seeking incentives of biobanking are constrained and limited (Tupasela, 2006). As such, sharing is considered by some to be a de facto necessity within the biobanking community. Data hugging, however, helps us identify alternative paths through which value can be generated within biobanking networks.

The network as a form of governance is equally an important historical pre-cursor to data-sharing practices in that networks of actors are the core constituents of data sharing, as opposed to hierarchical forms of governance (see Goldsmith and Eggers, 2004). In this context, research infrastructures, which include facilities, resources, or service infrastructures, provide an important backbone in facilitating the sharing of resources (Stahlecker and Kroll, 2013). Despite such policy and scientific efforts, some commentators have suggested that governments and supra-national policies have not adequately recognized nor addressed the reasons that hamper data-sharing practices (Pearce and Smith, 2011), and Larsson (2019) has argued that studies on research infrastructures have been neglected.

In this paper, I want to reflect on biobanking as emergent networks of authority and control over samples and data, with a focus on a specific biobanking network within the European context. Drawing on the empirically observed term of data hugging, which emerged in my interviews with biobankers, I suggest that membership in research networks does not always mean that actors share similar values or goals. Rather, network membership may also be the outcome of alternative strategies besides sharing through which value may be assessed and leveraged. Biobanking activities have a strong rooting within the academic community, although increasingly the field is becoming institutionally heterogeneous (public-private) where several commercial examples also exist. Responses to changing practices range from embracing new norms to strategic sharing, depending on the original goals and practices of each study and the new demands that may be placed on sharing practices. 


\section{Analytical Perspective - Sharing and Caring in Networks}

Mayrhofer and Prainsack (2009) have noted that networks of biobanks play a crucial role in the development of standards of practice among network members. The network concept is a central feature of BBMRI-ERIC, which seeks to connect national biobanking initiatives and national networks in Europe. The very premise of the network is the belief that samples and data are not being used efficiently, and too often sample collections are being replicated using public funds despite such samples already existing somewhere else. Many other such networks have been formed around global biobanking practices. The network approach is therefore crucial in understanding how biobanks operate and engage with multiple stakeholders in order to achieve and maintain long-term sustainability (Tupasela and Stephens, 2013; Cañada et al., 2015) and generate value.

Numerous biobanking actors and stakeholders have developed standards and codes of conduct for the sharing of data and samples between partners (Zika et al., 2010; Knoppers et al., 2011; Harris et al., 2012). Some commentators have suggested that we are witnessing an 'open data revolution' (de Silva and Vance, 2017), while others have argued that the non-use of samples and health-related data can cause harm (Jones et al., 2017). Numerous studies have also identified barriers to data and sample sharing (Milanovic et al., 2007; Colledge et al., 2013; Pereira, 2013; Verlinden et al., 2014), noting how there is a reluctance by clinicians and researchers to share data (Horn and Terry, 2012; Murtagh et al., 2016). Other studies have explored the challenges associated within national biobanking nodes (Larsson et al., 2018; Larsson, 2019), whereas Mascalzoni et al. (2015, p. 721) attribute institutional resistance to sharing to a fear that they will not receive recognition for their work and investment. Furthermore, Heeney (2017) has suggested that we are witnessing an ethical moment in data sharing, while Leonelli (2013) has noted how diverse and unstable research communities can hamper the building of large data infrastructures.

Science and Technology Studies (STS) literature has paid close attention to what allows for data and samples to move and not move between different actors (Star and Ruhleder, 1996; Urry, 2000; Meijer et al., 2012; Hoeyer et al., 2017; Tarkkala, 2019). Recent research on data work suggests that humans build relationships with the materials (samples and data) that they have collected and work with (Pinel, 2020; Pinel et al., 2020). In some cases, these relationships reflect commitments that researchers maintain toward the people from whom samples and data have been collected (Hoeyer et al., 2017), while in other cases it may also reflect other notions of care within scientific work (Friese, 2013).

In relation to not sharing, the biobanking community reflects classical studies related to how social change comes about in communities in relation 
to the uptake of new norms and practices (cf. Lewin, 1947, 1951). Larsson (2019) has used the notion of 'mindshare' to suggest the ways in which similar goals and strategies spread through organizations (Holt, 2004). Following Gottweis and Lauss (2012, p. 61), I build on the notion that biobanks are not just technical visions but rather intimately aligned within local and national strategic political processes in which access and use of resources is highly mediated by multiple forms of gatekeeping, as well as networking. Pinel et al. (2020) have suggested that researchers build long-term relationships with their data. Within the context of biobanking networks, I want to highlight that what counts as care differs greatly within networks of sharing. In this sense, data work and practices of care may entail very different definitions of what counts as good care depending on the actor.

Many biobanks and their principal investigators find themselves in situations that they did not originally envision for themselves regarding sharing. Although issues such as recognition and credit are important, the failure to share within biobanking networks can also be a broader political phenomenon with strategic interests (Tupasela, 2017, 2021). In this sense, decisions to share or not share have a performative and productive role, where biobank managers and researchers seek to meet expectations and commitments that they have made toward donors and participants. These commitments may be difficult to meet in relation to external sharing requirements. Among both biobanks and biobank networks, this may challenge the uptake of data and sample-sharing practices and norms.

The interest in sample and data sharing arises from the informants and the challenges that the lack of sharing is seen to pose to the cohesiveness and operation of the biobanking network in general. One of the guiding principles of developing a comprehensive European biobanking network by the research community itself has been to make visible and accessible the vast amount of sample collections around Europe. According to the BBMRI-ERIC memorandum of understanding (MoU) that each member signs as a condition of becoming a member of the network:

The aim of BBMRI is to establish, operate and develop a pan-European distributed research infrastructure of population-based and disease-oriented biobanks and biomolecular resources, in order to provide resources, facilities and support to high quality biological and medical research at all stages of the biomedical R\&D process. BBMRI will grant European researchers effective access to its resources and Common Services that include a joint IT service, and provision of scientific, technical, ethical and legal expertise. (BBMRI-ERIC MoU, N.A.) [emphasis added]

This task would reduce the unnecessary collection of samples, as well as make research more efficient by making existing collections more accessible and available to a broader community of researchers. Thus, the idea of a network has been to facilitate the more efficient use of existing sample and data 
collections. From this perspective, open data and sharing practices make sense and seem to be aligned with the development and enhancement of biobanking networks and standards within Europe (and elsewhere for that matter). It should be noted, however, that being a signatory does not mean that access to samples is a strict requirement because there are numerous considerations, such as quality of the research proposal and the amount of sample materials available, that may also play into this decision. As the BBMRI-ERIC Policy for Access to and Sharing of Biological Samples and Data states, 'individual biobanks remain in control over ultimately granting/denying access to potential users/requesters' (BBMRI-ERIC, 2020). The concern over sharing, however, addressed an issue regarding not being interested in contributing to the network at all, even when criteria for access were met and sample materials were available. In this sense, I argue that we need a better understanding of what counts as legitimate care practices within the network where members are expected to have a certain level of 'mindshare' regarding the values that are shared among its members.

For biobankers, researchers, and project PIs, however, the post-hoc implementation of new open access and sharing policies may run counter to the existing commitments that many may already have in practice. The result being that although many are willing to participate in the development of networks to make their collections more visible, there may be existing requirements that place restrictions on how and with whom sharing may be enacted. In addition to different commitments, biobanks possess limited numbers of samples, and they may place varying criteria on what types of projects they are willing to share samples for.

Sample and data sharing are also invariable associated with valuation practices (Tupasela, 2006). As Birch (2017) has suggested, the bioeconomy is a site where the creation and management of value is increasingly taking place (see also Birch and Muniesa, 2020). For public biobanks, however, the creation and management of value - particularly commercial value has been a consistent problem and challenge (Tupasela, 2006; Tupasela and Stephens, 2013). As an asset (both tissue and data) that research groups and hospitals have collected and maintained using public funds, the pressure to share the material without profit margins is far more significant than for private companies because the resource is considered to be a public resource and made readily available. The phenomena of data hugging, however, suggests that value creation and the conceptualization of samples and data as assets is far more complex and multi-faceted than what bioeconomy policies appear to suggest.

Within this context of contested data and sample sharing, this article seeks to identify a small but salient feature associated within the European biobanking community. I describe and discuss the notion of 'data hugging,' which emerged from my interviews with the biobanking community. 


\section{Material and Methods}

The empirical material of this article draws on three years of research (20152018) on biobanking networks in Europe, with a focus on the Biobanking and Biomolecular Resources and Research Infrastructure - European Research Infrastructure Consortium (BBMRI-ERIC).

During this period, I interviewed 22 stakeholders, including researchers, biobank managers, policymakers, and representatives from patient organizations. I sought informed consent from all participants to whom I had sent the research project description and study purpose beforehand. The interviews were semistructured and lasted usually around one hour. Some individuals were interviewed more than once, and informal discussions were held during coffee breaks and dinners associated with conferences and meetings that I attended and observed. Most interviews were conducted in English, but in some cases, Finnish was used as the interview language. I have translated the interviews conducted in Finnish.

All names of informants have been changed to preserve anonymity, and the excerpts that I use below are chosen so that people's identities remain anonymous. While conducting interviews and fieldwork, it became apparent that the policies and strategies to support and develop sample and data sharing were being met with different responses. Numerous informants were using the term 'data hugging' (Tupasela, 2017) to describe different practices in which samples and data were being shared using different criteria. Furthermore, the term appeared to have different connotations for different people.

From the interview material, as well as other publicly available documents, I identified common themes and concepts. The material was analyzed by paying attention to what factors gave rise to data hugging as a practice and its relationship to practices of sharing. Of interest became issues surrounding reputation and control of scarce resources as a way of maintaining legitimacy toward the original set of collaborators and partners.

\section{Data Hugging in Data/Sample Sharing}

Data hugging, as a concept used within the biobanking community, maintains some ambiguous characteristics, which I will address at the outset. First, the notion that data hugging refers only to data is misleading. In many instances in the interviews, people referred to the sharing of actual samples themselves and not data per se but still used the term data hugging to refer to this practice. Researchers extract data from the samples, but the interviews indicated that the term was being used interchangeably to refer to both data that had been derived from samples and samples themselves that had not yet been analyzed (see Mitchell and Thurtle, 2013; Tarkkala, 2019). Second, the notion of hugging took on two different meanings. The first, which was the most common, had a negative connotation to it meaning that something was not being shared and that the implication 
of this was that it was not aligned with what ought to be done with samples and data. The second perspective relating to hugging comes from an interest to care for the samples and data, as well as the ways in which they are used (cf. Pinel et al., 2020). This perspective derives from an interest by biobankers and custodians of samples and data to look after the samples and data. Caring for samples and data indicates commitments that extend beyond those related to sharing.

The forms of care, which I identified within this context, differ from previously described care practices in that they reflected a broader range of concerns that also included non-personal forms of commitment. As such, data hugging can come to have multiple meanings and connotations depending on which perspective it is being considered from. Within the data work perspective context, this bifurcation between hugging as a positive vs. negative activity goes beyond the current data care discussions, which suggests that researchers develop relationships with the data they produce. Caring for data cannot be dichotomized as either reflecting a normatively good vs. bad form of care; rather, different stakeholders define themselves what counts as good care.

Within the context of European biobanking, the normative context of sharing plays a very important role as I have discussed above. Consequently, the realization that there are network members who do not share common values or agreed upon practices that are inscribed into the network philosophy was frustrating to some members of the network. At the same time, this was an indication that members had very different conceptions of what good data work entailed. As one informant noted in an interview where we were discussing some of the challenges in developing a European biobank network:

But what was important at that time, and still is, that even when if it is less today, we still have the hugging problem that people don't want to share. They will not share some of the attribute. We also, as you know, have a very complicated ethical and legal structure in Europe. And so again there are attributes that you maybe don't want to share. (Interview with biobank administrator)

The hugging problem discussed in the interview was less of an issue than earlier but still something that warranted concern among many informants. In the interview, hugging was also attributed to ethical and legal differences between European countries. The excerpt shows how data and samples ('attributes') are shared strategically, in the sense that people may choose to share only parts of their data and sample collections for various reasons. This highlights how the discussions surrounding data and sample sharing need more nuance, whereby sharing is not necessarily a yes or no decision but can also represent a question of what is shared and made available to whom.

\section{Samples as a Common Good and Alignment}

The idea behind sharing samples and data derives from notions of a common good within the scientific community. Interestingly, in many of the interviews, 
Mertonian norms were discussed as a basis for practice. In one interview, a biobanker noted how she saw samples and data as common resources that everyone should be able to benefit from.

If everybody contributes, everybody could benefit from the general resource that is established. I think we are still too much influenced by the classical deal making type of arrangement - I give you something, I get something back - which helps but I think we should have a much more general approach. We are all contributing to common resource. There is not an immediate return. But you can participate from the whole resource which otherwise would not exist. So, it is a little bit like blood donation. You never know when you need it. But if nobody donates blood there is definitely no blood when you need it. And I will see the same if you don't expect this immediate return on recognition. The awareness that we all contribute into a common resource and I can/can't access the whole resource. (Interview with biobanker)

The biobanker makes a distinction between 'classical' deal making and what she considers a new way of sharing among the biobanking community. She discusses the classical model as a system of exchange between two partners, whereas the new model is aligned with blood donation as a model where the benefits of sharing may not be immediate in terms of returns. This type of juxtaposition between hugging and sharing was something that came up in several of the interviews. The comparison is an interesting one in that it aligns blood donation, which relates to a clinical need that is relatively immediate, to a research setting, where the benefits of the outcome may take years and decades to make its way to the clinic, if at all. The transfer of immediacy of sharing to the biobank context suggests that biobankers felt the need to highlight the importance of research using samples and sample-derived data. This aspect of sharing and the lack of sharing suggests that the biobanking community encompasses numerous different norms and that these norms are not always easily translated from one context to the next (cf. Lewin, 1947, 1951). This also suggests that attempts to construct the biobanking community as a sharing community with a similar mindshare are not always possible (Larsson, 2019).

It is important to note that the failure to share in one network does not mean that researchers are not sharing at all. It only means that they are not sharing within that network. Furthermore, it indicated how within the biobanking community there exist different definitions of value, as well as practice in relation to how and what needs to be shared.

Sample collections have an important temporal aspect to them that has considerable bearing on cultures of sharing. Some actors may be more inclined to share samples that have not had any use for many years and have just been lying dormant in storage without use. Some biobankers call such collections 'homeless' cohorts or collections in that their custodians may have retired or no one has had any use for them in a long time (see Kongsholm et al., 2018). In some 
national contexts, there may be policy- and legislation-driven initiatives to make sample collections and related data more available on a national scale (Salokannel et al., 2019). Other sharing cultures may be driven by a different set of practices, such as with the HeLa cells (Skloot, 2010). This problem was in some interviews identified as a problem of alignment within the scientific community.

There are different levels of aligning scientific communities. One is the institutional level, the university level, the national level, the European level. It can also be cross-sectoral. So, it is the different ways you can see how communities are aligned. And this was a little bit to some extent also our pioneering work here in country $\mathrm{X}$. Because we were really one of the first that set up a biobanking activity across all fields in medicine under the umbrella of the university. (Interview with policymaker)

This point highlights nicely how the biobanking community in Europe faces challenges at multiple levels. As Stanley and Stanley (1988) have suggested, institutional goals may differ greatly from individual goals and interests. Alignment of interests within a field that encompasses a broad range of individual actors ranging from geneticists to pathologists, as well as institutional actors from hospitals to research universities, poses challenges. Some individuals and institutions may be more willing to share than others, while others will be strategic in terms of what they share and do not share.

\section{Sharing a Scarce Resource}

Sometimes, the choice of not sharing may simply come down to not having enough of the physical samples to share with others. Other reasons for not sharing or choosing carefully what to share related to what types of tissue collections were in question.

With a lot of clinical biobanks, in particular, when it comes to tissues, it is an ending thing. So, your tissue will be used up, so you are extra careful with whom you are going to share. And typically, the biobanks, a lot of them were tissue banks, and they were not only the sample providers to some, they were also the sample users. So, the biobank was just set up for economizing on storage facility space and the like. (Interview with biobanker)

Many of the biobanks that were part of the network but chose to share very sparingly or not at all had other commitments to their own research community or even their patients whose samples also served as a record of their treatment and could not be shared because there were limited samples available. In many of the interviews, biobankers and researchers highlighted that samples are not an endless resource but a very scarce resource. Consequently, biobank managers, as well as the ethical review boards that oversee these activities, will have other responsibilities besides sharing alone. 
Sharing was also associated with other issues, such as research focus. Biobanks, which collected samples from rare diseases, were noted as being far more willing to share than others. In this context, sharing was predicated on the scarcity of resource. As one interviewee noted:

I think it depends a lot on the size of the countries. Rare diseases generally - and also the topics - rare diseases in general love to share. (Interview with biobanker)

The interest to share among the rare disease community stemmed from the fact that these researchers were used to dealing with scarce resources and already had a culture of sharing samples and data to further the study of rare diseases. For their disciplines, sharing was a requisite to conducting research, whereas for biobanks and researchers who had large collections for studying common diseases, this imperative was less apparent in their operations.

\section{Membership as Strategy}

There were strategic reasons involved with the decision to share or not.

Suddenly a shift started where a lot of communities didn't want to share, but they certainly wanted to know what the others have. And when you see that, you can only see what the others have, when you share as well, that is changing. And then I see a generation change all together - that people who are used to collaborate in international research projects, you had a good collaboration, not only scientifically but also on a personal level. [...] But personally, I still have the question for many biobanks: How open are they really? And here the individual biobanks differ quite a lot. (Interview with biobanker)

Being a member of the network (Mayrhofer and Prainsack, 2009) was a strategic way for many biobanks to see what other biobanks had in their collections and how they were running their operations. The practice of being a network member in order to see what others have without sharing plays a significant role in practices of valuation in biobanking. As I discussed above, the field of biobanking has been challenged with problems of pricing, value creation, and translation (Tupasela, 2006) given the fact that in many cases the samples and collections have been collected and are maintained with public funding (Tupasela and Stephens, 2013). Joining the BBMRI-ERIC network has allowed many to become aware of the biobanking market without sharing their samples or data. Price setting and cost calculation has proven to be difficult for many biobankers. In some cases, networks, such as the BBMRI large prospective cohort (BBMRI-LPC) network, have developed cost calculators to help members calculate the costs of sharing samples. In this sense, data hugging relates to practices of market valuation through different means than by sharing (Birch and Tyfield, 2013; Birch, 2017). The interviewee also noted that there are signs of a generational change, where the younger generation is more willing to share and see the benefits of sharing as outweighing the burdens. 


\section{Challenges of Recognition}

In several interviews biobankers noted that a major challenge that was associated with not sharing had to do with recognition. Recognition, merit, or incentive was something that came up repeatedly in interviews as a challenge even though this issue has been discussed among the biobanking community for quite some time (Kauffmann and Cambon-Thomsen, 2008; CambonThomsen et al., 2011; Napolitani et al., 2016; Howard et al., 2018). As one biobank administrator noted in an interview:

I think it is really the recognition of the contribution - and you get something back for it. And the wisest particularly evident in this hospital environment of biobanking because all the funding, all the impart funding activities. There is a lot of nonfunded voluntary contribution, which results in a very complex stakeholder situation. Because everybody here has contributed. Starting from the patients to doctors. They are all here for a stake in this common resource. In a big cohort, you have a program that funds. You can't employ, you can't pay for the people. The patients participate exactly for the reason of the study. But here it is very complex. The patients enter the hospital because he wants a treatment. And then people start to say, okay let's generate an added value out of this environment, which is an extremely complex stakeholder situation. And that is still a challenge how to deal with this stakeholder situation. And if someone does not feel properly recognized for his or her contribution, he is not happy. Very simple. And this might result in active or passive resistance in supporting projects and providing access. I think it is well understandable. It is clear. (Interview with biobanker)

As noted above, the context in which sample and data sharing takes place is not uniform; rather, networks of sharing encompass a very broad range of actors and situations in which samples have been collected and stored. The valuation of sample collections by being members of a network to see what others have is just one small part of the valuation process (Mayrhofer and Prainsack, 2009). Within large biobanking networks, the different members can have vastly different stakeholder structures, which means that the calculations and considerations that they may have regarding value and cost vary significantly. In data work and its relation to practices of valuation, this is significant because it shows that the market for generating assets and value is highly heterogeneous (Birch and Muniesa, 2020; Pinel et al., 2020). This means that it is difficult for different actors to generate comparable assets with similar value. This feature of biobanking networks makes it a challenge for biobanks to find suitable rates of exchange.

Although recognition for sharing data is becoming more of a merit in some contexts (cf. Phillips et al., 2020), there are still several concerns that hinder sharing of samples and data within the BBMRI network. One such concern deals with the fact that many of the important collections are in hospitals, where samples are maintained as a record of treatment and not intended (originally) for research. In some of the interviews, this was flagged as an issue 
because many of the pathologists or other physicians did not see the benefits of sharing their samples with researchers since they did not receive any benefits from such activities.

Why the hell should I do this? Just as other colleagues get fancy professions and fly around and are celebrated as the big shots and I do the hard work for them. This we can't solve. Because they have no benefit, no interest in utilizing this resource for their own research, because they don't do research but still are supporting. So here maybe other incentives would work more on the institutional level. A research university then supports those who contribute by other incentives like by providing a better working environment, some equipment that makes their life easier, so they say: Okay I do something for others, but I also get something that makes my work easier and better. Something like this. And that's the realization; biobanks require this institutional umbrella, otherwise you cannot develop these models. (Interview with biobanker)

The recognition of contribution was also identified in relation to the output of articles that had used samples from elsewhere. As one person noted in an interview:

And then I went out to all publications in PubMed to collect the information about biobanks. And it was a quite interesting exercise because I sort of got a ranking of countries who publish most in the field. But I was so sad about this when I started to read the publications. The biobanks were never mentioned. The samples were never mentioned. And at the same time there was a Nature article out there who said the same thing. It is extremely difficult to trace back which samples are used. So, we are working on that now. (Interview biobank manager)

The lack of merit or ability to trace which samples or resources have been used for the study has been a major concern for the biobanking community internationally. As such, it is something that the community has been working on for many years to solve. Although researchers or physicians from whom the samples have been received may become an author in a publication, the sample collection or biobank (also institution) rarely receives credit for the work and contribution that they have given to realize the research output. Even if this were mentioned, researchers could claim merit when applying for further funding or recognition of their work through very few evaluation metrics. In other words, the culture for recognizing sharing is still in its infancy within the biobanking community.

Interestingly, one of the issues that was not raised by the interviewees was that sharing can take place outside of the network and that biobankers may be members of several networks, both official as well as unofficial (personal networks). Therefore, the hugging concerns that were raised in these interviews may not reflect a lack of sharing in general but rather a lack of sharing within and among this network.

Recognition of contribution is further compounded by the fact that when samples are collected from a number of network members, then there is a 
dilution of contribution where the value of their credit becomes less significant depending on the number of samples or data amount that is being contributed to the project for which samples are being sought. The dilution issue was discussed considering how merit in general is measured in academia.

Yeah and so micro contribution ... what's the value of such a micro contribution? Absolutely, that's a very important issue. If it becomes so diluted it doesn't fly anymore. But I would like to dress it really more from a more general aspect. Namely, think about how our career systems work in academia. It is based on performance of individuals. All the indicators to access this performance are based on individual performance. And you are always compared with your colleague next door. And only if you are better than your colleague you get a better contract, the better position, the better resources, and so on. So, all our evaluation performance is essentially toxic to collaboration. We have no incentives if someone enables the success of someone else. We only collaborate if it helps our own success. Then we collaborate. That's reality. [...] Could there be other indicators that also evaluate the contribution of someone else's success? So the system could be, not that you have a very small share of each publication, but that you have another evaluation: have you enabled others' success and research. It's provocative, but I think it is worth thinking about. (Interview with biobanker)

The move toward a sharing culture in a system that rewards individual merits and success has been a major challenge within the biomedical research community, when resources, namely samples and data, are so fragmented and not controlled within a centralized system. As discussed above, there have been numerous efforts to develop metrics to evaluate the sharing of samples and data within the biobanking community, but the above quotation from an interview indicates that this is still a challenge. These findings are in line with those of Mascalzoni and colleagues who have identified the lack of recognition as a reason not to share (Mascalzoni et al., 2015). The tension between individual goals and more general notions of a common good were constantly present in the interviews.

\section{Sharing and Structural Concerns}

Sharing of samples and data within the European context related to structural concerns between member states. The BBMRI-ERIC framework is set up in such a way that in order to be a network member, member countries needed to contribute a certain percentage of their national gross domestic product (GDP) to the funding of the network infrastructure. This funding, however, did not guarantee adequate funding at the national level but rather could result in there being considerable inequalities between member states in relation to how biobanking activities were nationally funded. Furthermore, in some countries, such as Sweden, national funding was ceased completely because of tensions and problems at the national scale (cf. Larsson et al., 2018). 
And at the same time, we have had issues in BBMRI where in terms of the government structure the member states pay a certain annual fee based on the GDP and on top of that they should also fund the national networks. But given the economic crisis and changes of governments and people, this had not trickled through to everyone and here our members differ quite a lot, like in country $\mathrm{X}$ it was until recently basically one person who did the show who was very influential in terms of rare diseases and the key person here is called X. They managed somehow to get some additional funding for half a postdoc, and they're the only one basically in country X. They are hoping to get more research funding through BBMRI as well. And when we look at country $\mathrm{Y}$ where there was an evaluation of the already ongoing national network which was basically very good, but the government was looking for an excuse to cut down and said that 'Well, we are already paying for BBMRI so we can ... will not pay for you.' And of course, when the network contract came up again, they realized well it goes hand in hand that they have to include national funding as well. (Interview with policymaker)

Hugging, therefore, also had structural factors related to it, where biobanks were simply not able to find the funds that were needed to share, which has also been identified in previous research regarding barriers to sharing (Colledge et al., 2013; Verlinden et al., 2014). Some of this challenge, however, was addressed through the BBMRI-ERIC research infrastructure, when specific funding for sample handling and sharing was allocated to projects. This approach was meant to serve as a model and catalyst for national funding organizations to become aware of the hidden costs associated with sample handling and sharing, which had previously not been funded in grants to research applications or to biobanks themselves.

Within this context, sharing as a practice and a general ethos was associated with the availability of common funding for such tasks rather than personal commitments or relations with the samples and data that were available. The structural inequalities related to sharing also had a temporal dimension to it in relation to the long-term sustainability of biobanking. Sustainability has become a major discussion point among the international biobanking community (Vaught et al., 2011; Yuille et al., 2008).

\section{Translation}

Despite the development of European research infrastructures for biobanking, there are still major hurdles and obstacles to overcome in relation to developing successful and sustainable business models for biobanking.

It is a common resource, a common good that always requires common funding. So that is one thing. We must think about how to get some income to support. But this is more, let's say, to regulate and to help appropriate usage. The other thing is there might be a significant financial income in case a biobank contributed to developing an important new drug. Diagnostic, for example. Then some of these revenues can then flow back to finance the resource that provided the bases. But without a successful product - no way. Therefore, I think it is so important that biobanks become 
linked to innovation processes that can generate the value - financial value. And then you can explore new models that could have the substantial contribution to the financials. So, therefore, I think biobank really have to be linked to innovation processes. (Interview with policymaker)

The translation of a common resource into revenues from downstream products has been one of the major challenges within the biobanking community. Translation can be seen as a form of data work where researchers build long-term relations with their material (Pinel et al., 2020). Given that biobanks form a knowledge base from which a broad range of actors can seek to extract knowledge regarding the human genome represents the very beginning of the innovation process. Since the process is quite long in terms of drug development, for example, it was clear that biobankers are acutely aware of the challenge of tethering their upstream role to the final products and thus possible profits. Given that sharing infrastructures, such as BBMRI-ERIC, brand themselves as common resources, the expectations of a share of profits down the line seems quite unrealistic. This dilemma between being common resources and seeking profits from final products is a challenge in trying to tie added value to biobanking practices.

Within the interviews that I conducted, there was an apparent attempt to change the culture surrounding sharing within the biobanking community. The major challenge that appeared to hamper this was the fragmentation of the field, in the sense that samples and data could be used from numerous sources, ranging from individual researchers studying a specific rare disease, to large national prospective cohorts that had received public funding for their operations. Consequently, the alignment of so many different disciplinary and professional backgrounds to work toward a common ethos of sharing has been a challenge for the European biobanking network.

\section{Conclusion}

The sharing of data and resources within the scientific community has become a major political and scientific pre-occupation during the past decade (Gottweis and Petersen, 2008; Yuille et al., 2008; Kaye et al., 2009). Numerous commentators have indicated that governments, supra-national policies, and the scientific community have not adequately addressed the reasons that hamper data-sharing practices (Pearce and Smith, 2011) and that studies on research infrastructures have been neglected (Larsson, 2019). This concern has also been reflected among the European biobanking community, which has sought to develop research infrastructures to support the sharing of data and samples. Within this context, networks and membership within them have played an important role in the dissemination of values related to sharing and access to research resources (Mayrhofer and Prainsack, 2009).

Despite intensified efforts to encourage sharing within networks, there are still actors who have not embraced the shared norms and expectations of 
sharing. The term 'data hugging' has been explored as a form of data work through which some actors generate value. At the same time, however, data hugging generates tensions and frictions among those actors who have embraced the goals and expectations of sharing among network members.

One of the premises of the BBMRI-ERIC network has been that all participants share a common goal, as well as define the valuation processes of their sample and data collections in a similar way. According to Larsson (2019), the 'mindshare' perspective suggests that similar goals and strategies spread through organizations and networks (Holt, 2004). By drawing on previous STS work regarding data work and care practices (Friese, 2013; Pinel et al., 2020), I have argued that care can take on different and opposite meanings yet perform the same functions regarding practices of valuation and value generation. By this I mean that by not sharing, biobanks are establishing a value for their sample and data collections, just like those who share, except that they are performing this task using opposite methods (sharing vs. not sharing).

Although sharing is considered by some within the biobanking community to be a de facto necessity for generating value, data hugging helps us identify alternative paths through which value can be generated within biobanking networks. Following the STS discussions of the bioeconomy as a site of value creation (Tupasela, 2006; Birch and Muniesa, 2020), the practice of data hugging suggests that value and practices of valuation may take place in very different ways. The choice of not sharing as a way of generating value poses significant and interesting challenges to notions relating to the knowledge-based bioeconomy because it appears to be premised on the withholding of assets and resources, as opposed to sharing.

The bioeconomy policy discourse has heavily rested on commercial forms of valuation, which are seen to derive from data sharing strategies (OECD, 2001, 2006, 2009). As recent STS literature, however, has suggested, researchers develop personal ties with their data (Pinel et al., 2020). The findings of this study suggest that valuation of samples and data can have different meanings, which derive from alternative goals than those espoused within policy documents. Although some explanations derived from structural factors (Colledge et al., 2013; Verlinden et al., 2014), other findings suggest that recognition of work and effort in value creation is not well enough articulated within biobanking networks (cf. Kauffmann and Cambon-Thomsen, 2008; Cambon-Thomsen et al., 2011; Napolitani et al., 2016; Howard et al., 2018). As such, the study shows how practices of valuation within the bioeconomy discussions are more varied and intricate requiring more attention to how value creation recognizes work and effort by those involved in the value creation process (cf. Birch and Muniesa, 2020).

Choosing not to share may generate as much or even more value for biobankers as sharing itself. This insight, linked with the observation that caring practices differ significantly, suggests that the normative perspective of sharing as a 
commonly shared position within the biobanking community needs to be more nuanced. The difficulties within the biobanking community to generate traditional (measurable) forms of value, such as new medicines and patents, gives rise to a broader set of practices through which value is leveraged in relation to biobanks.

Biobanking policies regarding sharing should take a more flexible perspective on how samples and data are made available, as well as how value is defined and generated within these networks. The goals and approaches enshrined within the BBMRI-ERIC framework reflect the goals and aspirations of a small yet active group of biobankers in Europe. These biobankers' normative positions on what constituted proper sharing may not be shared by the research and clinical community, despite the political attempts to enshrine a form of sharing within the whole research area in Europe.

\section{Note}

1. Debates around the sharing of scientific data are not new but rather include discussions within numerous disciplines, including demography and other quantitative social sciences (e.g. birth cohorts' studies) from the 1930s onward (Ceci, 1988; Stanley and Stanley, 1988).

\section{Acknowledgement}

I am grateful to Heta Tarkkala, Madeleine Murtagh, and Michaela Th Mayrhofer for comments on earlier versions of this paper.

\section{Disclosure Statement}

No potential conflict of interest was reported by the author(s).

\section{Funding}

The research was supported financially by the University of Copenhagen's Excellence Programme for Interdisciplinary Research and the Kone Foundation.

\section{Note on contributor}

Aaro Tupasela is a sociologist with an interest in medical science and technology studies (STS). For the past 20 years he has been exploring different perspectives related to the biomedical collection and use of human tissue collections. His interests have focused on everyday practices in the international movement of samples and data within biobanking networks and research collaborations.

\section{ORCID}




\section{References}

BBMRI-ERIC (2020) BBMRI-ERIC Policy for access to and sharing of biological samples and data. Available at https://www.bbmri-eric.eu/wp-content/uploads/AoM_10_8_ Access-Policy_FINAL_EU.pdf (accessed 10 August 2020).

Birch, K. (2017) Rethinking value in the bio-economy: Finance, assetization, and the management of value, Science, Technology, \& Human Values, 42(3), pp. 460-490.

Birch, K. and Muniesa, F. (Eds) (2020) Assetization: Turning Things into Assets in Technoscientific Capitalism (Cambridge, MA: MIT Press).

Birch, K. and Tyfield, D. (2013) Theorizing the bioeconomy: Biovalue, biocapital, bioeconomics or ... what?, Science, Technology, \& Human Values, 38(3), pp. 299-327.

Cambon-Thomsen, A., Thorisson, G. A. and Mabile, L. (2011) The role of a bioresource research impact factor as an incentive to share human bioresources, Nature Genetics, 43(6), p. 503.

Cañada, J. A., Tupasela, A. and Snell, K. (2015) Beyond and within public engagement - a broadened approach to engagement in biobanking, New Genetics and Society, 34(4), pp. 355-376. doi:10.1080/14636778.2015.1105130

Ceci, S. J. (1988) Scientists' attitudes toward data sharing, Science, Technology, \& Human Values, 13(1-2), pp. 45-52.

Colledge, F., Elger, B. and Howard, H. C. (2013) A review of the barriers to sharing in biobanking, Biopreservation and Biobanking, 11(6), pp. 339-346. doi:10.1089/bio.2013. 0039.

De Silva P. U. K. and C. Vance. (2017) Sharing scientific data: Moving toward 'open data', in: Scientific Scholarly Communication. Fascinating Life Sciences (Cham: Springer). doi:10. 1007/978-3-319-50627-2_4

European Commission (2005) New Perspectives on the Knowledge-based Bio-Economy Transforming Life Sciences Knowledge into New, Sustainable Eco-Efficient and Competitive Products. Conference Report. Available at https://ec.europa.eu/research/ conferences $/ 2005 / \mathrm{kbb} / \mathrm{pdf} / \mathrm{kbbe}$ _conferencereport.pdf.

European Commission. (2010) EUROPE 2020 - a Strategy for Smart, Sustainable and Inclusive Growth (Brussels: European Commission).

European Society of Human Genetics (ESHG). (2003) Data storage and DNA banking for biomedical research: Technical, social and ethical issues, European Journal of Human Genetics, 11(Suppl. 2), pp. 8-10. doi:10.1038/sj.ejhg.5201115.

Florio, M. (2019) Investing in Science: Social Cost-Benefit Analysis of Research Infrastructures (Cambridge, MA: MIT Press).

Friese, C. (2013) Realizing potential in translational medicine: The uncanny emergence of care as science, Current Anthropology, 54(S7), pp. S129-S138.

Goldsmith, S. and Eggers, W. D. (2004) Governing by Network: The New Shape of the Public Sector (Washington, DC: Brookings Institution Press).

Gottweis, H. and Lauss, G. (2012) Biobank governance: Heterogeneous modes of ordering and democratization, Journal of Community Genetics, 3(2), pp. 61-72. doi:10.1007/ s12687-011-0070-0.

Gottweis, H. and Petersen, A. (Eds) (2008) Biobanks Governance in Comparative Perspective (London and New York: Routledge).

Goven, J. and Pavone, V. (2015) The bioeconomy as political project - a polanyian analysis, Science, Technology \& Human Values, 40(3), pp. 302-337.

Harris, J. R., Burton, P., Knoppers, B. M., Lindpaintner, K., Bledsoe, M., Brookes, A. J., ... Fortier, I. (2012) Toward a roadmap in global biobanking for health, European Journal of Human Genetics, 20(11), pp. 1105-1111. 
Heeney, C. (2017) An “ethical moment" in data sharing, Science, Technology, \& Human Values, 42(1), pp. 3-28.

Hoeyer, K., Tupasela, A. and Rasmussen, M. B. (2017) Ethics policies and ethics work in cross-national genetic research and data sharing: Flows, nonflows, and overflows, Science, Technology, \& Human Values, 42(3), pp. 381-404.

Holt, D. B. (2004) How Brands Become Icons: The Principles of Cultural Branding (Boston: Harvard Business Press).

Hood, L. and Rowen, L. (2013) The human genome project: Big science transforms biology and medicine, Genome Medicine, 5(9), p. 79.

Horn, E. J. and Terry, S. F. (2012) Biobanking challenges and informatics opportunities, in: R. L. Richesson and J. E. Andrews (Eds) Clinical Research Informatics, pp. 221-231 (London: Springer).

Howard, H. C., Mascalzoni, D., Mabile, L., Houeland, G., Rial-Sebbag, E. and CambonThomsen, A. (2018) How to responsibly acknowledge research work in the era of big data and biobanks: Ethical aspects of the Bioresource Research Impact Factor (BRIF), Journal of Community Genetics, 9(2), pp. 169-176.

Jones, K. H., Laurie, G., Stevens, L., Dobbs, C., Ford, D. V. and Lea, N. (2017) The other side of the coin: Harm due to the non-use of health-related data, International Journal of Medical Informatics, 97, pp. 43-51.

Kauffmann, F. and Cambon-Thomsen, A. (2008) Tracing biological collections: between books and clinical trials, Jama, 299(19), pp. 2316-2318.

Kaye, J., Heeney, C., Hawkins, N., de Vries, J. and Boddington, P. (2009) Data sharing in genomics - re-shaping scientific practice, Nature Reviews Genetics, 10, pp. 331-335. doi:10.1038/nrg2573.

Knoppers, B. M., Harris, J. R., Tassé, A. M., Budin-Ljøsne, I., Kaye, J., Deschênes, M. and Zawati, M. H. (2011) Towards a data sharing code of conduct for international genomic research, Genome Medicine, 3, p. 46.

Kongsholm, N. C. H., Christensen, S. T., Hermann, J. R., Larsen, L. A., Minssen, T., Pedersen, L. B., ... Schovsbo, J. (2018) Challenges for the sustainability of universityrun biobanks, Biopreservation and Biobanking, 16(4), pp. 312-321.

Langhof, H., Kahrass, H., Sievers, S. and Strech, D. (2017) Access policies in biobank research: What criteria do they include and how publicly available are they? A cross-sectional study, European Journal of Human Genetics, 25(3), pp. 293-300.

Larsson, A. (2019) Celling the concept: A study of managerial brand mindsharing of a distributed biobanking research infrastructure, Journal of Nonprofit \& Public Sector Marketing, 31(4), pp. 349-377.

Larsson, A., Savage, C., Brommels, M. and Mattsson, P. (2018) Structuring a research infrastructure: A study of the rise and fall of a large-scale distributed biobank facility, Social Science Information, 57(2), pp. 196-222.

Laurie, G. (2004) Genetic databases: Assessing the benefits and the impact on Human and patient rights - a WHO report, European Journal of Health Law, 11(1), pp. 87-92.

Leonelli, S. (2013) Why the current insistence on open access to scientific data? Big data, knowledge production, and the political economy of contemporary biology, Bulletin of Science, Technology \& Society, 33(1-2), pp. 6-11.

Lewin, K. (1947) Frontiers in group dynamics: II. Channels of group life, Social Planning and Action Research. Human Relations, 1(2), pp. 143-153.

Lewin, K. (1951) Field Theory in Social Science: Selected Theoretical Papers (New York: Harper).

Litton, J. E. (2018) Launch of an infrastructure for health research: BBMRI-ERIC, Biopreservation and Biobanking, 16(3), pp. 233-241. 
Mascalzoni, D., et al. (2015) International charter of principles for sharing bio-specimens and data, European Journal of Human Genetics, 23(6), pp. 721-728.

Mayrhofer, M. T. and Prainsack, B. (2009) Being a member of the club: The transnational (self-) governance of networks of biobanks, International Journal of Risk Assessment and Management, 12(1), pp. 64-81.

Meijer, A. J., Curtin, D. and Hillebrandt, M. (2012) Open government: connecting vision and voice, International Review of Administrative Sciences, 78(1), pp. 10-29.

Milanovic, F., Pontille, D. and Cambon-Thomsen, A. (2007) Biobanking and data sharing: A plurality of exchange regimes, Genomics, Society \& Policy, 23(1), pp. 17-30.

Mitchell, R. and Thurtle, P. (2013) Data Made Flesh: Embodying Information (New York: Routledge).

Murtagh, M. J., Turner, A., Minion, J. T., Fay, M. and Burton, P. R. (2016) International data sharing in practice: New technologies meet old governance, Biopreservation and Biobanking, 14(3), pp. 231-240.

Napolitani, F., Calzolari, A., Cambon-Thomsen, A., Mabile, L., Rossi, A. M., De Castro, P. and Bravo, E. (2016) Biobankers: Treat the poison of invisibility with CoBRA, a systematic way of citing bioresources in journal articles, Biopreservation and Biobanking, 14(4), pp. 350-352.

OECD. (2001) Biological Resource Centres: Underpinning the Future of Life Sciences and Biotechnology (Paris: OECD Publishing).

OECD. (2006) Creation and Governance of Human Genetic Research Databases (Paris: OECD Publishing).

OECD. (2009) The Bioeconomy to 2030: Designing a Policy Agenda (Paris: OECD Publishing). doi:10.1787/9789264056886-en.

Pearce, N. and Smith, A. H. (2011) Data sharing: Not as simple as it seems, Environmental Health, 10(1), pp. 1-7. doi:10.1186/1476-069X-10-107.

Pereira, S. (2013) Motivations and barriers to sharing biological samples: A case study, Journal of Personalized Medicine, 3(2), pp. 102-110.

Phillips, M., Molnár-Gábor, F., Korbel, J. O., Thorogood, A., Joly, Y., Chalmers, D., ... Knoppers, B. M. (2020) Genomics: Data sharing needs an international code of conduct, Nature, 578, pp. 31-33.

Pinel, C. (2020) When more data means better results: Abundance and scarcity in research collaborations in epigenetics, Social Science Information, 59(1), pp. 35-58.

Pinel, C., Prainsack, B. and McKevitt, C. (2020) Caring for data: Value creation in a dataintensive research laboratory, Social Studies of Science, 50(2), pp. 175-197.

Potocnik, J. (2005) New Perspectives on the Knowledge Based Bio Economy: Transforming Life Science Knowledge into Sustainable, Eco-Efficient and Competitive Products (Brussels: European Commission, DG Research).

Salokannel, M., Tarkkala, H. and Snell, K. (2019) Legacy samples in Finnish biobanks: Social and legal issues related to the transfer of old sample collections into biobanks, Human Genetics, 138(11), pp. 1287-1299.

Skloot, R. (2010) The Immortal Life of Henrietta Lacks (New York: Crown Publishin).

Stahlecker, T. and Kroll, H. (2013) Policies to Build Research Infrastructures in Europe: Following Traditions or Building New Momentum? (No. R4/2013). Arbeitspapiere Unternehmen und Region.

Stanley, B. and Stanley, M. (1988) Data sharing: The primary researcher's perspective, Law and Human Behavior, 12(2), p. 173.

Star, S. L. and Ruhleder, K. (1996) Steps toward an ecology of infrastructure: Design and access for large information spaces, Information Systems Research, 7(1), pp. 111-134. 
Tarkkala, H. (2019) Reorganizing biomedical research: Biobanks as conditions of possibility for personalized medicine, Doctoral dissertation, University of Helsinki, 2019.

Tarkkala, H., Helén, I. and Snell, K. (2019) From health to wealth: The future of personalized medicine in the making, Futures, 109, pp. 142-152.

Tripp, S. and Grueber, M. (2011) Economic impact of the human genome project, Battelle Memorial Institute, 58, pp. 1-58.

Tupasela, A. (2006) Locating tissue collections in tissue economies - deriving value from biomedical research, New Genetics and Society, 25(01), pp. 33-49.

Tupasela, A. (2017) Data-sharing politics and the logics of competition in biobanking, in: V. Pavone and J. Goven (Eds) Bioeconomies: Life, Technology and Capital in the 21st Century, pp. 187-206 (Cham, Switzerland: Palgrave).

Tupasela, A. (2021) Populations as Brands - Marketing National Resources for Global Data Markets (Palgrave Macmillan).

Tupasela, A. and Stephens, N. (2013) The boom and bust cycle of biobanking - thinking through the life cycle of biobanks, Croatian Medical Journal, 54(5), pp. 501-503.

Urry, J. (2000) Sociology Beyond Societies: Mobilities for the Twenty-First Century (London: Routledge).

Vaught, J., Rogers, J., Carolin, T. and Compton, C. (2011) Biobankonomics: Developing a sustainable business model approach for the formation of a human tissue biobank, JNCI Monographs, 2011(42), pp. 24-31.

Verlinden, M., Nys, H., Ectors, N. and Huys, I. (2014) Access to biobanks: Harmonization across biobank initiatives, Biopreservation and Biobanking, 12(6), pp. 415-422. doi:10. 1089/bio.2014.0034.

Viertler, C. and Zatloukal, K. (2008) Biobanking and Biomolecular Resources Research Infrastructure (BBMRI). implications for pathology, Der Pathologe, 29, pp. 210-213.

Yuille, M. M., Feller, P. I., Georghiou, L., Laredo, P. and Welch, E. W. (2008) Financial sustainability of biobanks: From theory to practice, Biopreservation and Biobanking, 15(2), pp. 85-92.

Zika, E., Paci, D., Braun, A., RijKers-Defrasne, S., Deschênes, M., Fortier, I., ... Ibarreta, D. (2010) Biobanks in Europe: Prospects for Harmonisation and Networking (No. JRC57831). Joint Research Centre (Seville site).

Zuiderwijk, A., Janssen, M., Choenni, S., Meijer, R. and Alibaks, R. S. (2012) Socio-technical impediments of open data, Electronic Journal of e-Government, 10(2), pp. 156-172. 